\title{
Clinical Feature and Prognostic Factors for Repeatedly Recurrent Spinal Chondrosarcoma: A Retrospective Study of 49 Patients in One Single Institution.
}

\author{
Yue Zhang \\ Shanghai Changzheng Hospital https://orcid.org/0000-0002-2829-0519 \\ Yuduo Xu \\ Shanghai Changzheng Hospital \\ Wenzhi Miao \\ Zhangjiagang Hospital \\ Haifeng Wei ( $\sim$ 490497487@qq.com ) \\ Department of orthopedic oncology, Changzheng Hospital, Second Military Medical University
}

\section{Research article}

Keywords: repeatedly recurrent spinal chondrosarcoma, prognosis, recurrence-free survival, overall survival, spine

Posted Date: February 25th, 2021

DOI: https://doi.org/10.21203/rs.3.rs-243623/v1

License: (c) (i) This work is licensed under a Creative Commons Attribution 4.0 International License. Read Full License 


\section{Abstract}

Background: To investigate the clinical feature in prognostic prediction of repeatedly recurrent spinal chondrosarcoma (RRSC). The purpose of this study was to illustrate the clinical parameters of RRSC and to discuss the prognostic factors by statistical analysis.

Methods: Univariate and multivariate analyses were performed to investigate independent prognostic factors for recurrence and death of patients with RRSC. Recurrence-free survival (RFS) and overall survival (OS) were estimated by Kaplan-Meier curve, and differences were analyzed by log-rank test. Factors with $\mathrm{P}<0.1$ extracted by univariate analysis were subjected to multivariate analysis by Cox regression analysis. $\mathrm{P}<0.05$ were considered statistically significant.

Results: Included in this study were 49 patients with RRSC who were followed up by a mean of 31.7 months (median, 25 months; range, 5-93 months). Local recurrence was detected in 33 patients, with death in 28 patients. The final statistical analysis indicated that wide surgical margin $(>4 \mathrm{~mm}$ ) was the most favorable prognostic factor for both recurrence-free survival (RFS) and overall survival (OS). Meanwhile, fewer number of recurrences (NOR) was in favor of RFS, and lower pathological grade was a significant favorable prognostic factor for OS.

Conclusion: Wide surgical margin should be considered in predicting the prognosis of RRSC, including RFS as well as OS. NOR was significant prognostic indicator for RFS, and pathological grading was significantly associated with OS.

\section{Introduction}

Chondrosarcoma is one of most common primary malignant bone tumor with local invasiveness, potential of recurrence, and high mortality, which usually occurs in patients between 30 and 70 years of age ${ }^{[1-3]}$. Chondrosarcoma consists of a family of malignant tumors in which the cells tend to differentiate into cartilage, classified as conventional, mesenchymal, dedifferentiated, clear cell and so on ${ }^{[4,5]}$. Owing to the anatomic constraints of the spine making it hard to achieve radical resection, the recurrence rate of spinal chondrosarcoma is maintained at a high level accounting approximately for $32 \%-58 \%{ }^{[6-8]}$. However, some patients experienced more than once recurrence resulting from high recurrent potential of spinal chondrosarcoma and inadequate surgical excision. Recurrent spinal chondrosarcoma (RSC), especially repeatedly recurrent spinal chondrosarcoma (RRSC), poses a huge challenge for surgeons and causes infinite pain and financial burden on patients. Patients with RRSC tend to experience the worse neurological defects and the greater surgical obstacles, resulting in malignant transformation, distant metastasis, or even death.

Although there was some published information about chondrosarcoma in the spine, they only focused on the prognosis of primary or recurrent spinal chondrosarcoma, rather than RRSC ${ }^{[9-11]}$. Treatment strategies of RRSC are scarce in published information and there is only clinical treatment about RSC on basis of some sporadic case reports, thus clinical treatment of RRSC is still controversial. Kawahara $\mathrm{N}$ et al have reported that total excision (total en bloc spondylectomy and total piecemeal spondylectomy) including wide tumor margin was beneficial for local control and overall survival of patients with RSC ${ }^{[12]}$. Moreover, Nisson PL et al have revealed that surgical technique that entering the tumor capsule showed a significantly great risk for recurrence ${ }^{[2]}$. However, all these reports contained a relatively small sample size, lacking of statistical significance. Some published information has confirmed a high level of efficacy for fractionated photon radiotherapy after surgery $[13,14]$.

The purpose of this retrospective study was to evaluate the significant prognostic factors for recurrence-free survival (RFS) and overall survival (OS) of patients with RRSC and to develop appropriate treatment options for these patients.

\section{Methods And Materials}

Patients

Page 2/14 
This retrospective study reviewed a total of 223 patients with spinal chondrosarcoma who treated surgically in our center between December 2001 and April 2017, from whom patients with twice or more time of recurrence were retrospectively included and their clinical data was obtained from the database of our hospital. The recurrence was detected by clinical manifestation and radiological outcome, and final prognosis was confirmed by pathological results of postoperative specimen. RRSC was defined as spinal chondrosarcoma that recurred twice or more time. Recruited in this retrospective study were 49 consecutive patients with RRSC underwent surgical treatment in this time period. Permission was obtained from the hospital ethic committee before commencing this research, and informed consent was obtained from all patients or their legal guardians. A typical case's material was shown in Fig. 1.

Patients' preoperative neurological status was evaluated according to Frankel score ${ }^{[15]}$. The resected chondrosarcoma was classified as conventional, mesenchymal, dedifferentiated, clear cell subtype on basis of histological appearance ${ }^{[16]}$. The

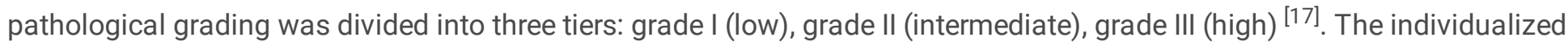
surgical strategy was decided for each patient according to Tomita classification, Ennecking stage, and Weinstein-BorianiBiagini surgical staging system ${ }^{[18-20]}$. This study focused on the recurrence and death status, with recurrence-free survival (RFS) and overall survival (OS). Event times were defined as the interval from the date of last surgery to local recurrence, death, or until April 2017 for living patients. All patients were followed up on an outpatient basis at 3-month intervals for the first 6 months, then at 6-mo intervals for the next 2 years, and annually.

\section{Statistical method}

Quantitative data are described by mean, median (range), and qualitative data are described as counts and percentages. The univariate and multivariate analysis of various clinical factors were performed to identify independent variables that could predict the prognosis of RRSC.

The RFS rate and OS rate were evaluated by the Kaplan-Meier method, and log-rank test was used for univariate analysis to identify independent variables that could predict prognosis. Clinical experience and statistical analysis were used to decide whether continuous variables should be categorized. Factors with $P$ value $<0.10$ were subjected to multivariate analysis by Cox proportional hazards analysis. $P$ value $<0.05$ were considered statistically significant. All statistical calculations were performed using SPSS Statistics, version 21.0 (IBM, Armonk, New York).

\section{Result}

\section{Patient baseline characteristics}

The clinical data of 49 patients with RRSC was described in Table 1. The population comprised 31 males and 18 females with a mean age of 44.2 years (median $37 \mathrm{y}$; range, 19-67y). Of these patients, 27 patients with NOR of two times, and the remaining 22 patients experienced more than two times. Moreover, 16 patients were performed first operation in our hospital, and 33 patients underwent first surgical treatment in other hospitals. Of them, 10 RRSCs located in cervical spine, with 30 cases, 5 cases, and 4 cases in thoracic spine, lumber spine, and sacrum, respectively. 15 RRSCs was classified as Tomita I-III, and the other was classified as Tomita IV-VI, according to Tomita classification. Simultaneously, 24 patients were diagnosed as with conventional RRSC, 8 with mesenchymal variants, 14 with dedifferentiated subtype, and 3 with clear cell RRSC. All 49 patients underwent surgical treatment; total en bloc spondylectomy, total piecemeal spondylectomy, and subtotal resection were performed in 9,23, and 17 cases, respectively. The surgical margin of 24 patients was narrow, while the remaining 25 cases were detected as wide margin.

Recurrence was detected in 33 patients after last surgical treatment, while 28 patients died during the follow-up period. The mean follow-up time was 31.7 months (median, 25 months; range, 5-93 months). The mean time from last surgery to recurrence was 13.4 months (median, 11 months; range, 3-68 months). while follow-up for the dead patients was 19.3 months (median, 16.5 months; range, 5-67 months). 
Postoperative recurrence was common in patients with RRSC, the overall RFS rate after last surgical treatment was $32.7 \%$, with mean RFS of 24.3 months (median, 17 months; range, 3-68 months). The detailed univariate analysis of prognostic factors for RFS was described in Table 1. In our series, the RFS of patients with tumor diagnosed as conventional subtype was longer than patients with other three subtypes, such as mesenchymal, dedifferentiated, and clear cell subtypes ( $p<$ 0.001). The recurrence rate was significantly different among patients with pathological grading I, II, and III $(p<0.001)$. In addition, intraoperative chemotherapy could obviously prolong the RFS of patients with RRSC $(p=0.080)$. Patients who experienced number of recurrence more than 2 times had shorter RFS than those underwent recurrence of 2 times $(p<$ 0.001). Statistical results revealed that first surgical institution was our hospital could significantly increase the RFS of patients with RRSC $(p=0.032)$. Moreover, patients with wide surgical margin had high RFS rate than those with narrow surgical margin $(p<0.001)$.

Twenty-eight patients (57.1\%) suffered death, thus the OS for RRSC was 42.9\%, with mean OS of 31.7 months (median, 25 months; range, 5-93 months). Univariate analysis of prognostic factors affecting OS was shown in Table 1. According to statistical results using log-rank test, a significant difference was found in patients' age $(p=0.079)$, histological subtype ( $p$ $<0.001)$, pathological grading $(p<0.001)$, postoperative radiotherapy $(p=0.077)$, NOS $(p<0.001), F S I(p=0.078)$, and surgical margin $(p<0.001)$, respectively.

\section{Multivariate analysis of prognostic factors affecting RFS and OS of patients with RRSC}

Potential prognostic factors extracted by univariate analysis were submitted to Cox proportional hazards analysis. Multivariate analysis of potential independent prognostic factors of RFS was shown in detail in Table 2. NOR was significantly associated with RFS of patients with RRSC (The hazard ratio [HR] was 0.240, $p=0.012$ ). Patients with wide surgical margin had longer RFS rate than those with narrow surgical margin (HR, 3.194; $p=0.002)$. The Kaplan-Meier curves of RFS for NOR and surgical margin were shown in Fig. 2. Moreover, the results of multivariate analysis of prognostic value for OS revealed that pathological grading and surgical margin were significant prognostic factors for OS of patients with RRSC in Table 3 (pathological grading: HR, 3.283; $p=0.012$ and surgical margin: HR, 0.216; $p=0.008$ ). And the Kaplan-Meier curves of OS for pathological grading and surgical margin were described in Fig.3.

\section{Baseline characteristics of patients underwent five surgical treatment}

Of all patients, 27 patients underwent two-times recurrence, 15 patients with three times, 7 patients with four times. The detailed baseline characteristics of seven patients underwent four-time recurrences were described in Table 4. Of them, only one patient (case\# 3) had first surgical treatment in our hospital after initial diagnosis. Thoracic spine was the most common location of lesion of RRSC with four recurrences. Only one tumor was classified as Tomita III according to radiological result (case\# 1). Two patients (case\# 2,4) experienced postoperative radiotherapy were dead during follow up. All patients with tumor evaluated as dedifferentiated spinal chondrosarcoma and pathological grading III were dead, while only one patient (case\# 3) was alive with disease and one patient (case\# 7) lived with no evidence of disease.

\section{Discussion}

Chondrosarcoma is one of most common bone tumor constituting a family of malignant tumors in which the cells tend to differentiate into cartilage $[21,22]$. With special anatomical structure and high recurrent potential, how to reduce postoperative recurrent rate and improve postoperative survival time poses a great challenge for treatment of RRSC. Therefore, prolong the RFS and improve the OS are still important issues that should be addressed for surgeons. In our series, univariate and multivariate analysis were performed to identify the independent prognostic factors for RFS and OS of patients with RRSC. The final statistical results revealed that wide surgical margin could significantly improve RFS and 
OS. Low NOR was a significantly independent prognostic factor for RFS of patients with RRSC. Moreover, pathological grading was regarded as significant prognostic factor for OS.

In our research, mean age of 44.2 years and peak incidence between 30-70 years of age were similar with the finding of former reports $[9,23,24]$. The male to female rate was $1.1: 1$, which was different from previous published results. Yin $\mathrm{H}$ et al reported that the male to female rate of spinal chondrosarcoma was 2.1:1 [9]. Armin Arshi et al found that the male to female rate of this disease was 1.8:1, according to the SEER registry from 1973 to 2012 [11]. However, age and gender were not significant independent prognostic factor for RFS and OS. Nevertheless, Yin $\mathrm{H}$ et al has reported that total en bloc spondylectomy could significantly decrease the risk of recurrence and meanwhile improve overall survival of spinal chondrosarcoma [9]. Armin Arshi et al thought that radiotherapy worsens outcomes in patients with confined and locally invasive disease [11].

Surgical treatment is the standard treatment strategy for RRSC, with the aim of preserving or even improving functionality, relieving pain, controlling local recurrence, and promising prolonged survival. As for patients in this series, all patients experienced local recurrence (LR) at least two times, even with seven patients with four-time LR. There were 27 patients with number of recurrence of 2 times, 15 patients with 3 times, and 7 patients with 4 times. Scar hyperplasia in the lesion of patients with tumor recurrence leads to unclear boundary structure in surgical area, which is easy to damage the nerve function during the reoperation, aggravate the neurological dysfunction, increase the possibility that the tumor can't be completely removed, and trigger the recurrence of the tumor [25]. Thus, achieving gross total resection of spinal chondrosarcoma with wide margin in first operation was extremely important for prognosis of patients. Therefore, the first operation opportunity is precious for both doctors and patients [26,27]. Eva Roos et al had reported that the 5-year outcome after recurrent chondrosarcoma was lower than primary chondrosarcoma [28]. Meanwhile, our study revealed that less NOR can significantly reduce the risk of recurrence of patients with RRSC.

According to the introduction of the current $\mathrm{WHO}$ classification of tumors of soft tissue and bone, chondrosarcoma was grouped into three pathological grades, such as I, II, and III [29]. Chondrosarcoma grade I officially termed atypical cartilaginous tumor is recommended curettage with local adjuvant therapy. However, Chondrosarcoma grade II and III with histologically fat binuclear cells and multinucleated giant cells are advised to undergo total en bloc spondylectomy. As for recurrent cases, total en bloc spondylectomy was difficult to be achieved. Multivariate analysis indicated that patients with tumor classified as pathological grade III had poorer OS than those with tumor classified as pathological grade I and II, which was consistent with previous reports [1,30,31]. Among tumor's histology, four subtypes of chondrosarcoma were included in our series, such as conventional, mesenchymal, dedifferentiated, and clear cell subtypes. Nevertheless, no significant association between histological subtype and prognosis was confirmed in this research. Armin Arshi et al found that mesenchymal and dedifferentiated chondrosarcomas portended a comparatively dismal prognosis in the spine [11]. Wu AM et al reported that pediatric patients with myxoid variants had a poorer prognosis than patients with chondrosarcoma not otherwise specified [32]. Van Maldegem A et al thought that prospective studies need to be conducted based on preclinical work to develop a uniform regimen to treat advanced chondrosarcoma patients according to the diagnosed histological subtype to improve their survival [33].

Surgical margins were measured on the histological slides in centimeters from the resection surface to the nearest viable tumor, which were grouped into narrow surgical margin and wide surgical margin. Meanwhile, narrow margin included marginal and intralesional surgical margins. However, the definition of an adequate resection margin is still a matter of debate and various classification have been proposed [34,35]. For example, the assessment of a circumferential resection margin in $\mathrm{mm}$ has been suggested by Wittekind et al and Jonathan D et al [36,37]. Simultaneously, an anatomical barrier at the closest margin is significantly vital to the RFS and OS in chondrosarcoma of the bone [38,39]. Uniform criteria with histopathological assessment of the distance in $\mathrm{mm}$ and the presence of biological barriers are necessary for the reproducibility of future research. Jonathan D et al suggested that surgeons should aim to achieve a 4-mm margin in all 
grades to reduce the risk of local recurrence and its effect on OS [37]. Surgical margin was regarded as a significant role in RFS and OS statistically in grade-II and grade-III chondrosarcoma, the most common grades of chondrosarcoma.

It is well established in the literature that chondrosarcomas are as an entity resistant to radiation and chemotherapy [40,41]. Recent research revealed that radiotherapy improves survival in patients with metastatic disease and worsens outcomes in patients with confined and locally invasive disease [11]. The study of Chen D et al suggested that low-grade chondrosarcoma of the osseous spine is resistant to radiotherapy, while high-grade chondrosarcoma patients had a better trend with radiotherapy [42]. Vasudevan HN et al have reported that fractionated stereotactic radiotherapy was an effective adjuvant or salvage treatment for chondrosarcoma. Drilon AD et al highlighted the poor response rate to chemotherapy and emphasizes aggressive control of localized disease as the primary approach to management [43]. Thus, multidisciplinary treatment of chondrosarcoma is controversial.

To our knowledge, our study is the largest series of RRSC to date. However, there are some limitations. First, it is a retrospective study with all the limitations thereof. Second, as a surgical series, it only focused on patients who were underwent surgical treatment. Third, the duration of follow-up was not long enough.

\section{Conclusion}

Surgical margin confers RFS and OS benefits in patients with repeatedly recurrent chondrosarcoma in the spine, so surgeons should aim to achieve a wide margin in all grades RRSC for better prognosis. Less NOS is favorable factor for RFS, and high pathological grade of RRSC was significant risk factor for OS.

\section{List Of Abbreviations}

RRSC: repeatedly recurrent spinal chondrosarcoma; RSC: recurrent spinal chondrosarcoma RSC; LR: local recurrence; RFS: recurrence-free; OS: overall survival; NOR: number of recurrence; FSI: first surgical institution; TC: Tomita classification; HS: histological subtype; PG: pathological grading; AT: adjuvant therapy; FT: follow-up time; M: male; F: female; T: thoracic; L: lumber; P: posterior way; SS: subtotal spondylectomy; IC: intraoperative chemotherapy; PR: postoperative radiotherapy; PC: postoperative chemo-therapy; DOD: dead of disease; AWD: alive with disease; NED: no evidence of disease.

\section{Declarations}

\section{Availability of data and materials}

All the data of the manuscript are presented in the paper or additional supporting files.

\section{Ethics approval and consent to participate}

All procedure involving human participants performed in studies were approved by Changzheng hospital ethics committee, and informed consents were obtained from all patients or their legal guardians.

\section{Consent for publication}

Patients or their legal guardians know and approve the publication.

\section{Availability of data and material}

All the data of the manuscript are presented in the paper or additional supporting files.

\section{Competing interests}


No conflict of interest exits in the submission of this manuscript, and manuscript is approved by all authors for publication. I would like to declare on behalf of my co-authors that the work described was original research that has not been published previously, and not under consideration for publication elsewhere, in whole or in part.

\section{Funding}

No funding supports this study.

\section{Authors' Contributions}

Haifeng Wei and designed the study and gave us several meaningful suggestions. Yuduo Xu reviewed and collected the medical records. Wenzhi Miao analyzed and interpreted the patient data. Yue Zhang was a contributor in writing the manuscript. All authors read and approved the final manuscript.

\section{Acknowledgements}

No acknowledgements to declare.

\section{References}

1. Fromm J, Klein A, Baur-Melnyk A, Knösel T, Lindner L, Birkenmaier C, et al (2018) Survival and prognostic factors in conventional central chondrosarcoma. BMC Cancer 18(1):849.

2. Nisson PL, Berger GK, James WS, Hurlbert RJ (2018) Surgical Techniques and Associated Outcomes of Primary Chondrosarcoma of the Spine. World Neurosurg 119: e32-e45.

3. Song K, Shi X, Wang H, Zou F (2018) Can a Nomogram Help to Predict the Overall and Cancer-specific Survival of Patients with Chondrosarcoma? Clin Orthop Relat Res 476(5):987-996.

4. Ma X, Meng G, Wang K, Li D, Wang L, Li H, et al (2019) The Differences Between Intracranial Mesenchymal Chondrosarcoma and Conventional Chondrosarcoma in Clinical Features and Outcomes. World Neurosurg 122: e1078e1082.

5. Jeong W, Kim HJ (2018) Biomarkers of chondrosarcoma. J Clin Pathol 71(7):579-583.

6. Nishizawa K, Mori K, Saruhashi Y, Takahashi S, Matsusue Y (2014) Long-term clinical outcome of sacral chondrosarcoma treated by total en bloc sacrectomy and reconstruction of lumbosacral and pelvic ring using intraoperative extracorporeal irradiated autologous tumor-bearing sacrum: a case report with 10-years follow-up. Spine J 14(5): e1-8.

7. Strike SA, McCarthy EF (2011) Chondrosarcoma of the spine: a series of 16 cases and a review of the literature. lowa Orthop J 31:154-9.

8. Goda JS, Ferguson PC, O'Sullivan B, Catton CN, Griffin AM, et al (2011) High-risk extracranial chondrosarcoma: longterm results of surgery and radiation therapy. Cancer 117(11):2513-9.

9. Yin H, Zhou W, Meng J, Zhang D, Wu Z, Wang T, et al (2014) Prognostic factors of patients with spinal chondrosarcoma: a retrospective analysis of 98 consecutive patients in a single center. Ann Surg Oncol 21(11):3572-8.

10. Boriani S, De lure F, Bandiera S, Campanacci L, Biagini R, Di Fiore M, et al (2000) Chondrosarcoma of the mobile spine: report on 22 cases. Spine (Phila Pa 1976) 25(7):804-12.

11. Arshi A, Sharim J, Park DY, Park HY, Bernthal NM, Yazdanshenas H, et al (2017) Chondrosarcoma of the Osseous Spine: An Analysis of Epidemiology, Patient Outcomes, and Prognostic Factors Using the SEER Registry From 1973 to 2012. Spine (Phila Pa 1976) 42(9):644-652.

12. Kawahara N, Tomita K, Murakami H, Demura S, Yoshioka K, Miyazaki T (2010) Total excision of a recurrent chondrosarcoma of the thoracic spine: a case report of a seven-year-old boy with fifteen-years follow-up. Spine (Phila 
Pa 1976) 35(11): E481-7.

13. Potluri S, Jefferies SJ, Jena R, Harris F, Burton KE, Prevost AT, et al (2011) Residual postoperative tumour volume predicts outcome after high-dose radiotherapy for chordoma and chondrosarcoma of the skull base and spine. Clin Oncol (R Coll Radiol) 23(3):199-208.

14. Foweraker KL, Burton KE, Maynard SE, Jena R, Jefferies SJ, Laing RJ, et al (2007) High-dose radiotherapy in the management of chordoma and chondrosarcoma of the skull base and cervical spine: Part 1-Clinical outcomes. Clin Oncol (R Coll Radiol) 19(7):509-16.

15. Frankel HL, Hancock DO, Hyslop G, et al (1969) The value of postural reduction in the initial management of closed injuries of the spine with paraplegia and tetraplegia. I. Paraplegia 7(3): 179-192.

16. Logie Cl, Walker EA, Forsberg JA, Potter BK, Murphey MD (2013) Chondrosarcoma: A Diagnostic Imager's Guide to Decision Making and Patient Management. Semin Musculoskelet Radiol 17(2):101-15.

17. Rosenberg AE (2013) WHO Classification of Soft Tissue and Bone, fourth edition: summary and commentary. Curr Opin Oncol 25(5):571-3.

18. Tomita K, Kawahara N, Kobayashi T, et al (2001) Surgical strategy for spinal metastases. Spine. 26(3):298-306.

19. Enneking WF (1986) A system of staging musculoskeletal neoplasms. Clin Orthop Relat Res (204):9-24.

20. Boriani S, Weinstein JN, Biagini R (1997) Primary bone tumors of the spine. Terminology and surgical staging. Spine 22(9): 1036-1044.

21. Laitinen MK, Parry MC, Le Nail LR, Wigley CH, Stevenson JD, Jeys LM (2019) Locally recurrent chondrosarcoma of the pelvis and limbs can only be controlled by wide local excision. Bone Joint J 101-B(3):266-271.

22. Zoccali C, Baldi J, Attala D, Rossi B, Anelli V, Annovazzi A, Ferraresi V (2018) Intralesional vs. extralesional procedures for low-grade central chondrosarcoma: a systematic review of the literature. Arch Orthop Trauma Surg 138(7): $929-937$.

23. Shives TC, McLeod RA, Unni KK, Schray MF (1989) Chondrosarcoma of the spine. J Bone Jt Surg Am 71(8):1158-65.

24. Schoenfeld AJ, Hornicek FJ, Pedlow FX, et al (2012) Chondrosarcoma of the mobile spine: a review of 21 cases treated at a single center. Spine (Phila Pa 1976) 37(2):119-26.

25. Kim HS, Bindiganavile SS, Han I (2015) Oncologic outcome after local recurrence of chondrosarcoma: Analysis of prognostic factors. J Surg Oncol 111(8):957-61.

26. Çitak N, Çelikten A, Metin M, Pekçolaklar A, Gürses A (2011) Radical resection of a giant recurrent chondrosarcoma of the anterior chest wall. Gen Thorac Cardiovasc Surg 59(7): 512-4.

27. Wang Q, Chen H, Zhou S (2015) Chondrosarcoma of the larynx: report of two cases and review of the literature. Int $J$ Clin Exp Pathol 8(2):2068-73.

28. Roos E, van Coevorden F, Verhoef C, Wouters MW, Kroon HM, Hogendoorn PC, et al (2016) Prognosis of Primary and Recurrent Chondrosarcoma of the Rib. Ann Surg Oncol 23(3):811-7.

29. Coindre JM (2012) New WHO classification of tumours of soft tissue and bone. Ann Pathol 32(5 Suppl): S115-6.

30. Yoshimura Y, Isobe K, Arai H, Aoki K, Kito M, Kato H (2013) Preoperative radiographic and histopathologic evaluation of central chondrosarcoma. Arch Orthop Trauma Surg 133(9):1225-31.

31. Van Oosterwijk JG, de Jong D, van Ruler MA, Hogendoorn PC, Dijkstra PD, van Rijswijk CS, et al (2012) Three new chondrosarcoma cell lines: one grade III conventional central chondrosarcoma and two dedifferentiated chondrosarcomas of bone. BMC Cancer 12:375.

32. Wu AM, Li G, Zheng JW, Chen CH, Chen D, Qiao ZG, et al (2019) Chondrosarcoma in a paediatric population: a study of 247 cases. J Child Orthop 13(1):89-99.

33. van Maldegem A, Conley AP, Rutkowski P, Patel SR, Lugowska I, Desar IME, et al (2019) Outcome of First-Line Systemic Treatment for Unresectable Conventional, Dedifferentiated, Mesenchymal, and Clear Cell Chondrosarcoma. Oncologist 24(1):110-116. 
34. Hoang K, Gao Y, Miller BJ (2015) The Variability in Surgical Margin Reporting in Limb Salvage Surgery for Sarcoma. lowa Orthop J 35:181-186.

35. Enneking WF, Spanier SS, Goodman MA (1980) A system for the surgical staging of musculoskeletal sarcoma. Clin Orthop Relat Res 153:106-120.

36. Hodel S, Laux C, Farei-Campagna J, Götschi T, Bode-Lesniewska B, Müller DA (2018) The impact of biopsy sampling errors and the quality of surgical margins on local recurrence and survival in chondrosarcoma. Cancer Manag Res 10:3765-3771.

37. Stevenson JD, Laitinen MK, Parry MC, Sumathi V, Grimer RJ, Jeys LM (2018) The role of surgical margins in chondrosarcoma. Eur J Surg Oncol 44(9):1412-1418.

38. Mckee MD, Liu DF, Brooks JJ, et al (2004) The prognostic significance of margin width for extremity and trunk sarcoma. J Surg Oncol 85(2):68-76.

39. Sadoski C, Suit HD, Rosenberg A, Mankin H, Efrd J (1993) Preoperative radiation, surgical margins, and local control of extremity sarcomas of soft tissues. J Surg Oncol 52(4):223-230.

40. Holliday EB, Mitra HS, Somerson JS, et al (2015) Postoperative proton therapy for chordomas and chondrosarcomas of the spine. Spine (Phila Pa 1976) 40:544-9.

41. La Rocca RV, Morgan KW, Paris K, Baeker TR (1999) Recurrent chondrosarcoma of the cranial base: a durable response to ifosfamide-doxorubicin chemotherapy. J Neurooncol 41(3):281-3.

42. Chen D, Chen CH, Zhang LL, Lin ZK, Zheng JW, Phan K, et al (2018) Chondrosarcoma of the Osseous Spine Treated by Surgery With or Without Radiotherapy: A Propensity Score Matched and Grade/Stage-stratified Study. Clin Spine Surg 31(6): E310-E316.

43. Drilon AD, Popat S, Bhuchar G, D'Adamo DR, Keohan ML, Fisher C, et al (2008) Extraskeletal myxoid chondrosarcoma: a retrospective review from 2 referral centers emphasizing long-term outcomes with surgery and chemotherapy. Cancer 113(12):3364-71.

\section{Tables}


Table 1.

Patients' characteristics and univariate analysis of prognostic factors affecting recurrence and survival of RRSC

\begin{tabular}{|c|c|c|c|c|c|}
\hline \multirow[t]{2}{*}{ Factors } & \multirow[t]{2}{*}{ Number } & \multicolumn{2}{|c|}{ Recurrence-free survival } & \multicolumn{2}{|l|}{ Overall survival } \\
\hline & & $\begin{array}{l}\text { median time } \\
\text { (months) }\end{array}$ & $\mathrm{p}$ value & $\begin{array}{l}\text { median time } \\
\text { (months) }\end{array}$ & $p$ value \\
\hline \multicolumn{6}{|l|}{ Gender } \\
\hline Male/female & $31 / 18$ & $21 / 11$ & 0.271 & $33 / 19$ & $0.079 *$ \\
\hline \multicolumn{6}{|l|}{ Age } \\
\hline$<50 \mathrm{y} />=50 \mathrm{y}$ & $30 / 19$ & $13 / 21$ & 0.250 & $21 / 33$ & 0.975 \\
\hline \multicolumn{6}{|l|}{ DOS } \\
\hline$<12 \mathrm{mon} />=12 \mathrm{mon}$ & $39 / 10$ & $17 / 11$ & 0.146 & $25 / 21.5$ & 0.362 \\
\hline \multicolumn{6}{|l|}{ PFS } \\
\hline$A-C / D-E$ & $25 / 24$ & $12 / 21$ & 0.177 & $21 / 33$ & 0.109 \\
\hline \multicolumn{6}{|l|}{ Tumor location } \\
\hline Cervical/thoracic/lumber/sacral & $10 / 30 / 5 / 4$ & $12.5 / 19 / 15 / 21$ & 0.690 & $18.5 / 30 / 20 / 44.5$ & 0.594 \\
\hline \multicolumn{6}{|l|}{ Involved segment } \\
\hline Monosegment/multisegment & $19 / 30$ & $21 / 13$ & 0.150 & $32 / 20.5$ & $0.097 *$ \\
\hline \multicolumn{6}{|l|}{ Ennecking grading } \\
\hline$|-||/| I \mid$ & $25 / 24$ & $15 / 19$ & 0.487 & $24 / 26.5$ & 0.506 \\
\hline \multicolumn{6}{|l|}{ Tomita classification } \\
\hline I-III/IV-VI & $15 / 34$ & $21 / 14.5$ & 0.235 & $33 / 21$ & 0.104 \\
\hline \multicolumn{6}{|l|}{ Histological subtype } \\
\hline \multicolumn{6}{|l|}{ Conventional/mesenchymal/ } \\
\hline Dedifferentiated/clear cell & $24 / 8 / 14 / 3$ & $28.5 / 18 / 4 / 8$ & $<0.001^{\star}$ & $41 / 27.5 / 12.5 / 8$ & $<0.001^{*}$ \\
\hline \multicolumn{6}{|l|}{ Pathological grading } \\
\hline I/II/III & $17 / 23 / 9$ & $33 / 17 / 5$ & $<0.001^{\star}$ & $52 / 24 / 8$ & $<0.001^{*}$ \\
\hline \multicolumn{6}{|l|}{ Surgical pathway } \\
\hline Anterior/posterior/combined & $4 / 32 / 13$ & $52.5 / 16 / 14$ & 0.594 & $52.5 / 26 / 21$ & 0.200 \\
\hline \multicolumn{6}{|l|}{ Surgical method } \\
\hline $\begin{array}{l}\text { Subtotal/total piecemeal/ total en- } \\
\text { bloc }\end{array}$ & $17 / 23 / 9$ & $17 / 10 / 19$ & 0.793 & $21 / 17 / 28$ & 0.515 \\
\hline \multicolumn{6}{|l|}{ Intraoperative chemotherapy } \\
\hline Yes/no & $24 / 25$ & $21 / 14$ & $0.080 *$ & $28 / 21$ & 0.178 \\
\hline \multicolumn{6}{|l|}{ Postoperative radiotherapy } \\
\hline Yes/no & $10 / 39$ & $33.5 / 14$ & 0.114 & $41 / 21$ & $0.077^{*}$ \\
\hline
\end{tabular}




\begin{tabular}{|c|c|c|c|c|c|}
\hline Yes/no & $14 / 35$ & $15.5 / 32$ & 0.874 & $24 / 39$ & 0.566 \\
\hline \multicolumn{6}{|l|}{ NOR } \\
\hline 2 times/ $>2$ times & $27 / 22$ & $32 / 11$ & $<0.001^{*}$ & $33 / 16$ & $<0.001^{*}$ \\
\hline \multicolumn{6}{|l|}{ FSI } \\
\hline Our hospital/others & $23 / 16$ & $29 / 12$ & $0.032^{*}$ & $34.5 / 28$ & $0.078^{\star}$ \\
\hline \multicolumn{6}{|l|}{ Surgical margin } \\
\hline Narrow margin/wide margin & $24 / 25$ & $11.5 / 33$ & $<0.001^{\star}$ & $17.5 / 39$ & $<0.001^{\star}$ \\
\hline \multicolumn{6}{|c|}{ * Indicates statistical significance $(p<0.10)$} \\
\hline
\end{tabular}

Table 2.

Multivariate analysis of the prognostic factors affecting recurrence-free survival of RRSC

\begin{tabular}{|lllll|}
\hline Factors & $\mathrm{B}$ & $\mathrm{HR}$ & $95 \% \mathrm{Cl}$ & $\mathrm{p}$ value \\
\hline Histological subtype & 0.331 & 1.393 & $0.878-2.209$ & 0.159 \\
\hline Pathological grading & 0.550 & 1.732 & $0.896-3.351$ & 0.103 \\
\hline Intraoperative chemotherapy & 0.505 & 1.658 & $0.719-3.823$ & 0.236 \\
\hline NOR & 1.189 & 3.283 & $1.296-8.318$ & $0.012^{\square}$ \\
\hline FSI & 0.488 & 1.629 & $0.681-3.897$ & 0.273 \\
\hline Surgical margin & -1.147 & 0.317 & $0.132-0.762$ & $0.010^{\square}$ \\
\hline Indicates statistical significance ( $<<0.05)$ & & \\
\hline NOR: number of recurrence; FSI: first operative institution; HR: hazard radio \\
\hline
\end{tabular}


Table 3.

Multivariate analysis of prognostic factors affecting overall survival of RRSC

\begin{tabular}{|lllll|}
\hline Factors & $\mathrm{B}$ & $\mathrm{HR}$ & $95 \% \mathrm{Cl}$ & $\mathrm{p}$ value \\
\hline Age & 0.164 & 1.178 & $0.470-2.954$ & 0.726 \\
\hline Involved segment & 0.240 & 1.272 & $0.498-3.246$ & 0.615 \\
\hline Histological subtype & 0.446 & 1.562 & $0.909-2.684$ & 0.106 \\
\hline Pathological grading & 1.189 & 3.283 & $1.304-8.265$ & $0.012^{\square}$ \\
\hline Postoperative radiotherapy & 0.980 & 2.666 & $0.658-10.798$ & 0.169 \\
\hline NOR & 0.648 & 1.912 & $0.643-5.679$ & 0.244 \\
\hline FSI & 0.152 & 1.164 & $0.433-3.134$ & 0.763 \\
\hline Surgical margin & -1.532 & 0.216 & $0.069-0.674$ & $0.008^{\square}$ \\
\hline Indicates statistical significance $(\mathrm{p}<0.05)$ & & \\
\hline NOR: number of recurrence; FSI: first operative institution; HR: hazard radio \\
\hline
\end{tabular}

Table 4

Baseline characteristics of patients underwent more than three recurrences.

\begin{tabular}{|c|c|c|c|c|c|c|c|c|c|c|c|c|}
\hline No & Sex & Age & NOR & $\mathrm{FSI}$ & Location & $\mathrm{TC}$ & HS & PG & Surgery & AT & $\begin{array}{l}\text { FT } \\
\text { (month) }\end{array}$ & Status \\
\hline 1 & $M$ & 49 & 4 & other & T3-5 & III & conventional & II & $\begin{array}{l}\text { P, SS, } \\
\text { IC }\end{array}$ & No & 24 & DOD \\
\hline 2 & $M$ & 51 & 4 & other & L1-2 & VI & dedifferentiated & III & $\begin{array}{l}\text { P, SS, } \\
\text { IC }\end{array}$ & PR & 7 & DOD \\
\hline 3 & $\mathrm{~F}$ & 63 & 4 & $\begin{array}{l}\text { our } \\
\text { hospital }\end{array}$ & $\mathrm{T} 4-6$ & IV & conventional & II & P, SS & No & 13 & AWD \\
\hline 4 & M & 43 & 4 & other & $\mathrm{T} 4-5$ & V & dedifferentiated & III & $\begin{array}{l}\text { P, SS, } \\
\text { IC }\end{array}$ & PR & 23 & DOD \\
\hline 5 & $\mathrm{~F}$ & 52 & 4 & other & T12-L1 & $\mathrm{VI}$ & dedifferentiated & III & P, SS & $\mathrm{PC}$ & 19 & DOD \\
\hline 6 & $M$ & 67 & 4 & other & T7 & V & conventional & II & $\begin{array}{l}\text { P, SS, } \\
\text { IC }\end{array}$ & No & 11 & DOD \\
\hline 7 & M & 42 & 4 & other & T8-9 & IV & mesenchymal & II & P, SS & No & 5 & NED \\
\hline
\end{tabular}

\section{Figures}


A

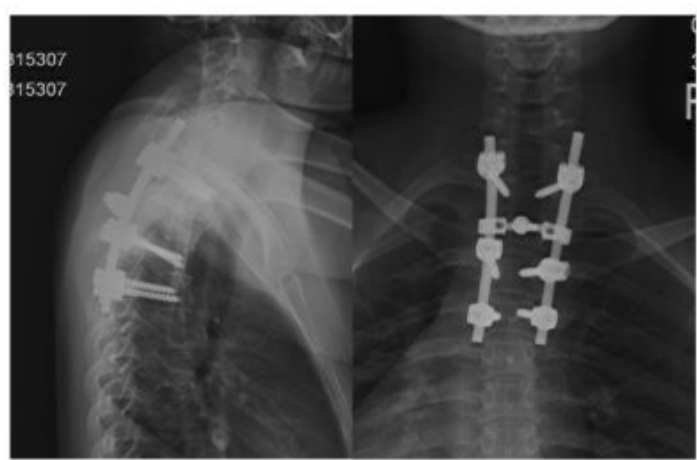

C

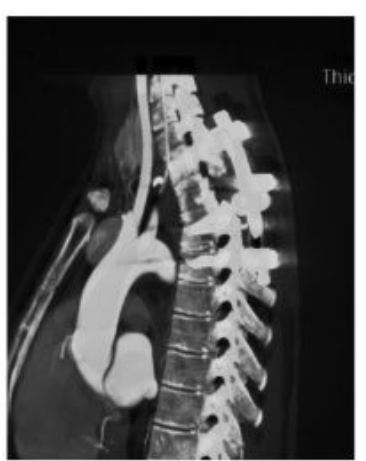

$\mathrm{D}$
$\mathrm{B}$
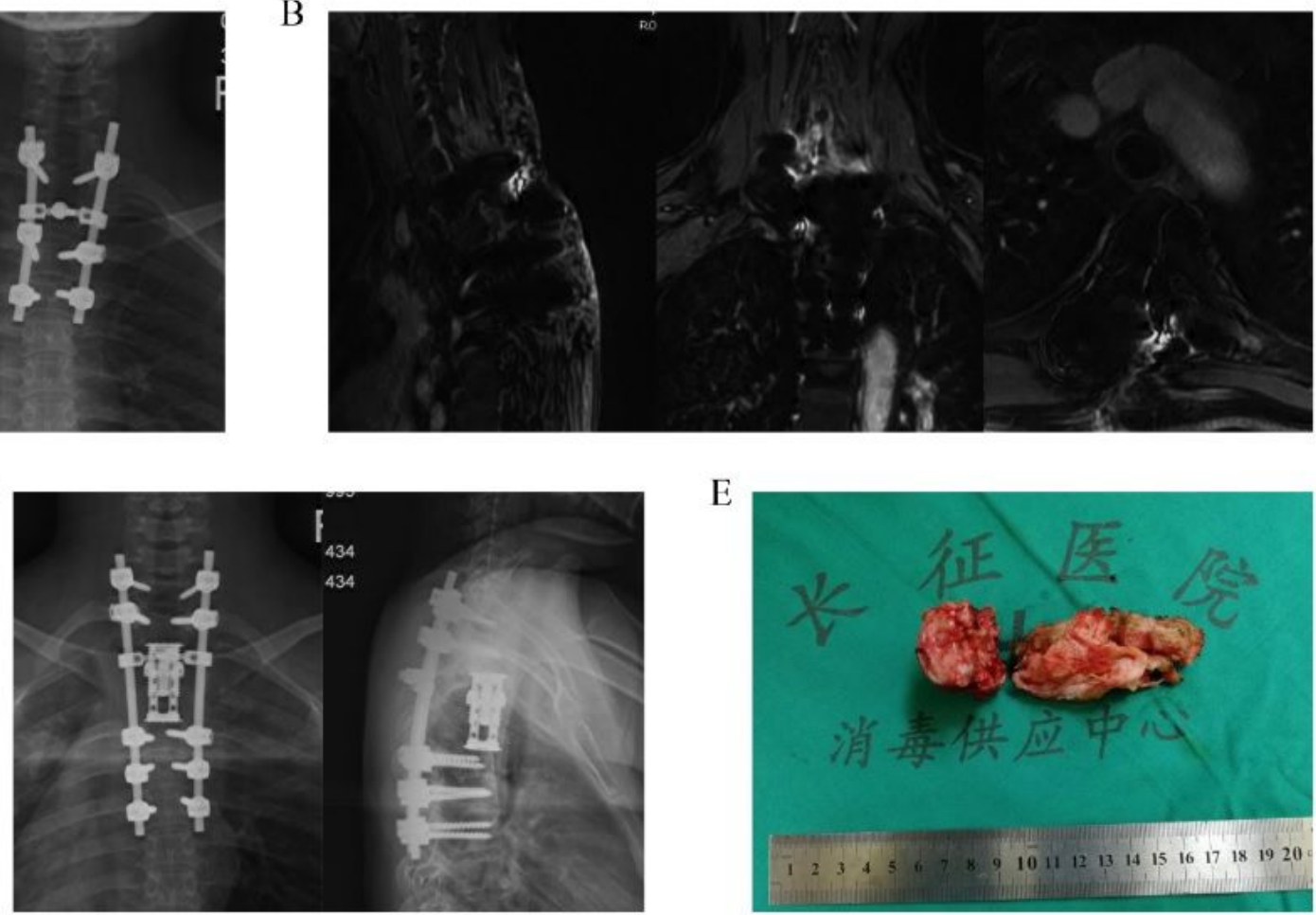

$\mathrm{E}$

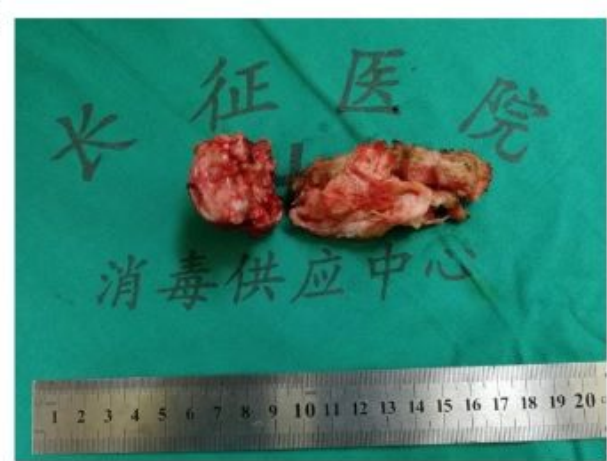

\section{Figure 1}

A typical case underwent the removal of tumor by total en bloc spondylectomy in our center and was diagnosed as recurrent spinal chondrosarcoma. (A) Preoperative X-rays of anteroposterior and lateral spine demonstrated straightening of thoracic physiological curvature, metal fixed shadow, and osseous destruction from second thoracic spine to third thoracic spine. (B) Preoperative magnetic resonance imaging (MRI) indicated that the tumor recurred in enhanced image. (C) Preoperative CT showed osteolytic destruction from second thoracic vertebrae to third thoracic vertebrae and its posterior elements, paravertebral soft tissue mass, and compression of spinal cord. CT=computed tomography. (D) The postoperative X-rays showed the second and third thoracic spines were removed and replaced by artificial vertebral body, with solid internal-fixation. (E) The specimen of the tumor by total en bloc resection. 


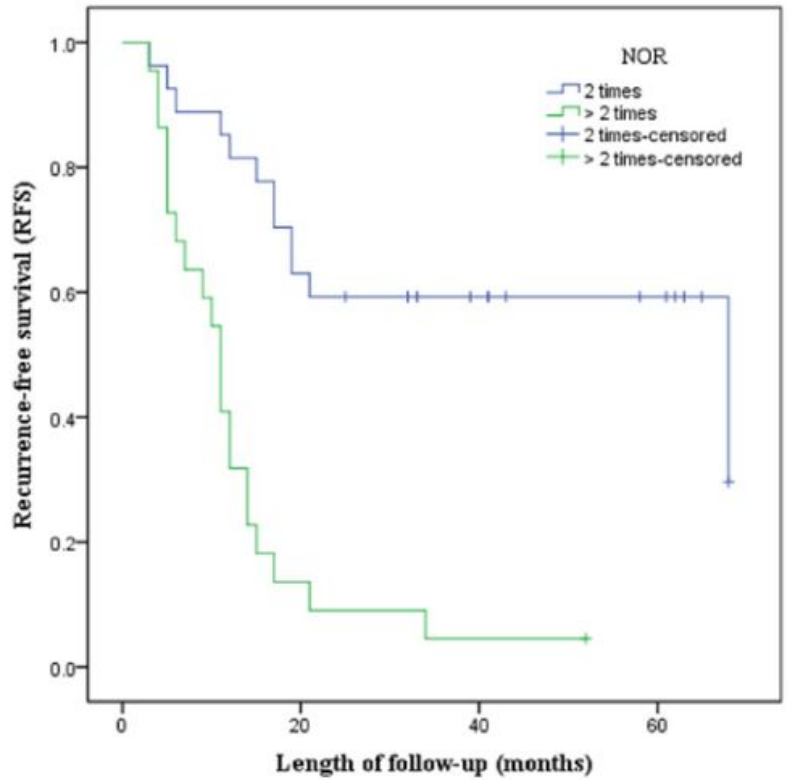

A

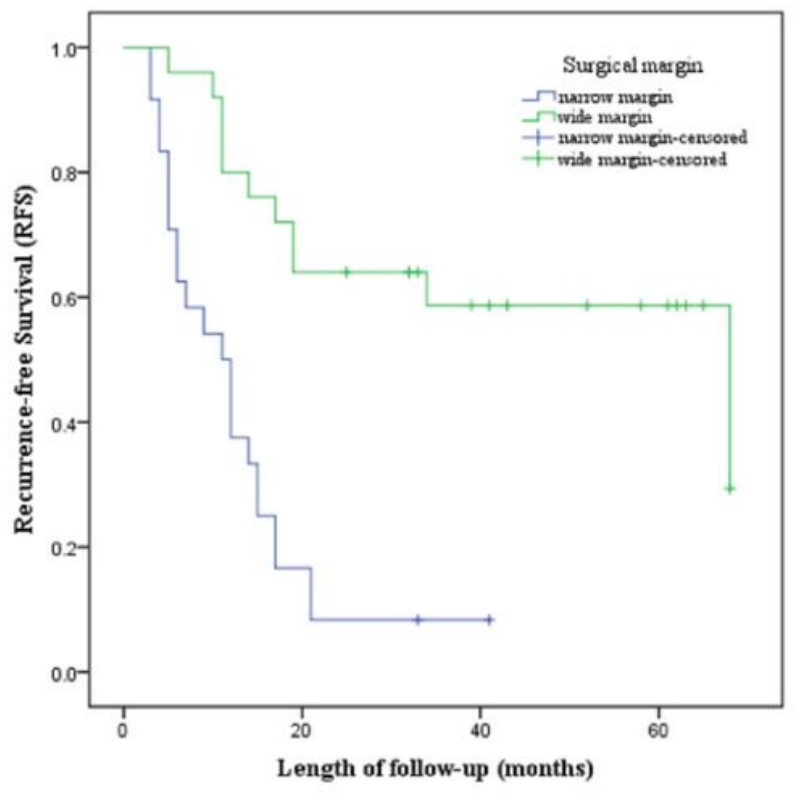

B

Figure 2

(A) Kaplan-Meier curves of recurrence-free survival for NOR. (B) Kaplan-Meier curves of recurrence-free survival for surgical margin.

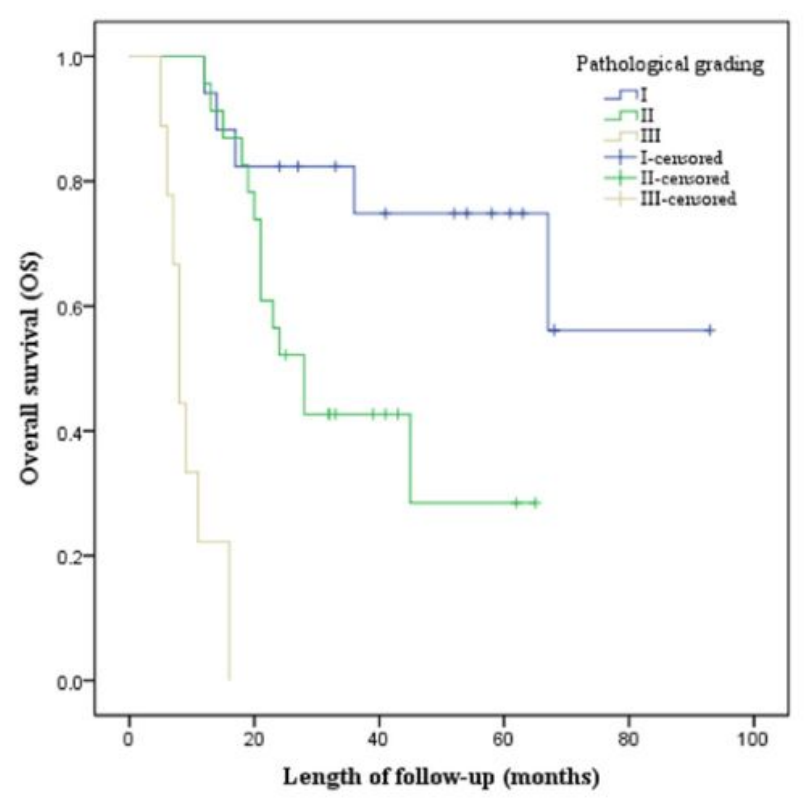

A

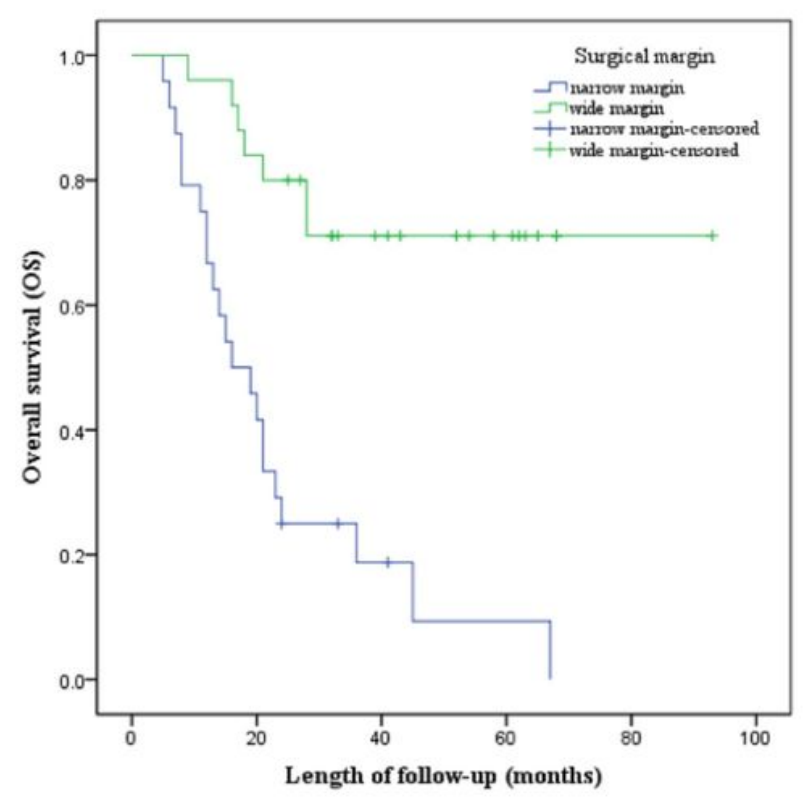

B

\section{Figure 3}

(A) Kaplan-Meier curves of overall survival for pathological grading. (B) Kaplan-Meier curves of overall survival for surgical margin. 